\title{
Short Communication: Determination of the age of the Paddy Field Frog, Fejervarya cancrivora (Anura: Dicroglossidae) by using skeletochronology
}

\author{
NI LUH PUTU RISCHA PHADMACANTY ${ }^{1, \boldsymbol{}, ~ H E L L E N ~ K U R N I A T I ~}$ \\ Museum Zoologicum Bogoriense, Research Center for Biology, Indonesian Institute for Sciences. Jl. Raya bogor Km 46, Cibinong, Bogor16911, West \\ Java, Indonesia,. Tel./fax.: +62-21-8765056, `email: rischa.phadmacanty@gmail.com
}

Manuscript received: 14 August 2019. Revision accepted: 29 August 2019.

\begin{abstract}
Phadmacanty NLPR, Kurniati H. 2019. Short Communication: Determination of the age of the Paddy Field Frog, Fejervarya cancrivora (Anura: Dicroglossidae) by using skeletochronology. Biodiversitas 20: 2739-2743. The age of 102 individuals of paddy field frog (Fejervarya cancrivora) from Karawang District, West Java, Indonesia was skeletochronological determined. Hematoxylinophilic lines interpreted as lines of arrested growth (LAG) were observed clearly in the femur bone suggesting that this technique can be used to estimate the age of the frog, although the level of accuracy is likely to be strongly influenced by external and internal factor. In general, age estimates look close to accuracy at mature age levels; which one LAG equals the age of the frog that has passed one year old. The age structure of $F$. cancrivora from a paddy field in Karawang District has the maximum age of five years in females and four years in males. In general, adult females were not significantly larger than adult males.
\end{abstract}

Keywords: Age, body size, Fejervarya cancrivora, sexual maturity, skeletochronology

\section{INTRODUCTION}

Fejervarya cancrivora is an anuran amphibian that is distributed in Indonesia, including Java, Sumatra, Kalimantan and Bali (Iskandar 1998; Kurniati 2003; Kusrini 2013). Despites its wide distribution, so far there is very little information on age estimation of this species. Skeletochronology method is commonly used for retrospective age estimation of amphibians with unknown recapture history (Andreon et.al. 2011; Castanet et.al. 1996; Guarino and Erismis 2008; Sinsch 2015), and the best method to asses population age structure (Guarino et.al. 2003; Kutrup et.al. 2005; Olgun et.al. 2005). A preliminary study of Indonesian frog age by using skeletochronology on $F$. cancrivora, $F$. limnocharis and Limnonectes macrodon were done by Kusrini and Alford (2006) They reported that the maximum number of LAGs (Line of Arrested Growth) from 35 samples (SVL=14.5$56.7 \mathrm{~mm}) \quad F$. cancrivora was one. The results of skeletochronological research which was conducted by Phadmacanty et al. (2018) for F. limnocharis found varied number of LAGs, so did the Pancharatna and Dehpande (2003) result, while Kusrini and Alford (2006) also only found one LAG on 103 samples ( $\mathrm{SVL}=15.68-53.00 \mathrm{~mm}$ ).

Bone parts that are commonly used in skeletochronological research are the phalanx bones (Eden et al. 2007; Guarino and Eresmis 2008; Hasumi 2010; Liao and $\mathrm{Lu}$ 2010a; Liao and $\mathrm{Lu}$ 2010b; Liao et al. 2011; Morrison et al. 2004; Olgun et al. 2005; Oromi et al. 2012); but the femur can also be used (Castanet et al. 1996; Kutrup et al. 2005; Sinsch and Dehling 2017). However, Pancharatna and Deshpande (2003) reported that tibia and fibula bones can be used forskeletochronological research without any significant difference result in one individual frog. The aim of this study is to determine the formation of LAG on F. cancrivora's bone which can estimate the age of the frog. Skeletochronology by using femur bones was applied in this study because based on Kusrini and Alford (2006), the toe phalanx bone was not adequate in age estimating of the F. cancrivora.

\section{MATERIALS AND METHODS}

\section{Field techniques}

Specimens of $F$. cancrivora were collected in the rice fields of Anggadita and Gintung Villages, Klari Sukaresmi Sub-district, Karawang District (GPS: S 06020'38,2 "; E 107020 '59,1 ") on March 16-29, 2018. The area of paddy field is one of the locations where $F$. cancrivora are harvested for human consumption. The main purpose in collecting individual frogs was for the study of endoparasites of the frogs. A total number of specimens for this study is 102 individuals which are a series of age levels, i.e. pre-adult and the adult stage. All of the specimens were preserved in $96 \%$ ethanol.

\section{Skeletochronology}

The specimens were residual of endo-parasitic studies. The femur bones were collected for skeletochronology studied. The skeletochronology analysis followed Sinsch (2015) used paraffin method. The decalcification process was modified from nitric acid to formic acid. The samples were washed out in tap water overnight and then decalcified in $10 \%$ of formic acid and stained using Erlich's hematoxylin. The samples were embedded in 
paraffin and sectioned in 15 um thickness with a rotary microtome (Yamato RV-240). Samples were deparaffinized by xylene, mounted by enthelan and analyzed by a compound microscope at 200x-400x magnification (Nikon Optiphot 2, Japan) attached to a computer for photographic analysis.

\section{Assessments of sexual maturity}

Sexual maturity was assessed based onthe secondary characteristics that appeared on male and female. Mature males are indicated by the appearance of dark color on the throat, precisely around the vocal sac area; whereas the adult female were observed by looked at the abdomen cavity; usually, prospective eggs inside the oviduct section can be seen on females that are already in mature age.

\section{Data analyses}

The PAST software (Hammer et al. 2001) was used to analyze data from measured parameters within sex and age groups. The Pearson's statistical correlation was used to estimate the correlation between SVL and the number of LAGs, and ANOVA Welch F test in the case of unequal variances was used to prove whether the growth SVL of adult males was significantly different from the growth SVL of adult females at level $\mathrm{p}<0.05$. Body growth followed von Bertalanffy curve by analyzing average SVL for females and males and the curve were shaped using MS excel version 2016.

\section{RESULTS AND DISCUSSION}

\section{Results}

The total number of individuals that was studied by skeletochronology was 102 . They consisted of 23 juveniles, 42 males, and 37 females. Results of the skeletochronology analysis is shown in Table 1.

Cross sections of the femurs looked like a thick circle as part of the bone, and in the thick inner circle (lumen), the bone marrow could be seen clearly (Figure 1). However, in juvenile and adult frogs, the circle bone layer was getting thicker and the lumen was getting narrower. The number of LAG detected was 0 (no LAG) to 5 LAGs. The presence of the growth zone and the number of LAG in cross-section femur bone are shown in Figure 1. On the cross-section, metamorphosis line (ML) was clearly detected in the femur bone for several histology cross sections (Figure 1). Part of this was clear in the phalanx bone as observed by Andreone et al. (2011) or by Liao and $\mathrm{Lu}$ (2010a) with the line named as Kastschenko Line (KL).
The number of LAGs with the increase in SVL for total individuals showed a positive correlation (Pearson linear, $\mathrm{r}=0.64, \mathrm{n}=102$ ); however, correlation on each age group yielded a strong positive correlation for the pre-adult group (Pearson linear, $\mathrm{r}=0.66, \mathrm{n}=23$ ) and adult female group (Pearson linear, $\mathrm{r}=0.78, \mathrm{n}=37$ ), but weakly positive correlation for adult male group (Pearson linear, $r=0.38$, $\mathrm{n}=42$ ). Based on correlation analyses, growth pattern of $F$. cancrivora was fast in juvenile stage and became slow in adult males. Body growth in adult males followed the von Bertalanffy curve, but it has not been proven in female.

Growth was estimated using the von Bertalanffy curve (Sinsch and Dehling 2017); however, in this study the growth was taking into account only the adult stages of females and males, because the sex of juveniles was unknown and froglets at metamorphosis stage were not collected. To determine the initial length of both sexes, the smallest juvenile length was taken as the beginning of SVL length (Rocha 1995). The shape of the curve is shown at Figure 2. Curve equation for females was $y=32.952 \mathrm{ln}$ $(\mathrm{x})+14.405 ; \mathrm{r}^{2}=0.8887$ and for males was $\mathrm{y}=19.317 \mathrm{ln}$ $(x)+20.807 ; r^{2}=0.8731$; based on these equations, male and female individuals that were examined in this study had strong correlation on body growth.

The juvenile group with SVL of less than $30 \mathrm{~mm}$ has 0 1 LAG; males had a yearly LAG between 0-4, while females had 0-5 LAG. The results of the correlations of three individual groups (pre-adult, adult female and adult male) can be seen in Figure 2. The uncommon case was found in adult female groups; there were three individuals who had entered the adult stage in length of SVL but apparently did not have LAG. In this case, the females' gonads were clear without any black spots as a sign of the early stage of the egg. The three individuals that have an uncommon case were also involved in the statistical analysis.

Based on 102 individuals that were analyzed by comparing the number of LAG and SVL, it appeared that some individuals did not show normal phenomena of one LAG equal to a one-year-old frog. The SVL for pre-adult stage, adult male and adult female ranges were between 17.70-29.70 mm, 30.60-65.20 mm, 31.10-89.10 mm respectively, but the formation of LAG in some individuals were not in equal to the increase the SVL, therefore there were an overlap SVL with the number of LAGs in the three groups. The result of this study found that 35 individuals (5 individuals of juveniles; 14 individuals of adult females and 16 individuals of adult males) had one LAG (Table 1). It was concluded that individuals with one LAG have passed the one-year period of their lifespan.

Table 1. Number of LAG, SVL range and SVL mean \pm Standart Deviation (SD) of Fejervarya cancrivora for each age and sex classes

\begin{tabular}{|c|c|c|c|c|c|c|c|c|c|}
\hline \multirow{2}{*}{$\begin{array}{c}\text { Number of } \\
\text { LAG }\end{array}$} & \multicolumn{3}{|c|}{ Juveniles (SVL $\leq \mathbf{3 0} \mathbf{~ m m})$} & \multicolumn{3}{|c|}{ Adult Female } & \multicolumn{3}{|c|}{ Adult Male } \\
\hline & $\begin{array}{l}\text { Number of } \\
\text { individual }\end{array}$ & Range & $\begin{array}{c}\text { Mean } \pm \\
\text { SD }\end{array}$ & $\begin{array}{l}\text { Number of } \\
\text { individual }\end{array}$ & Range & Mean \pm SD & $\begin{array}{l}\text { Number of } \\
\text { individual }\end{array}$ & Range & $\begin{array}{l}\text { Mean } \pm \\
\text { SD }\end{array}$ \\
\hline 0 & 18 & $17.70-29.70$ & $24.95 \pm 3.63$ & 14 & $31.10-46.60$ & $35.76 \pm 4.03$ & 13 & $30.60-61.10$ & $38.08 \pm 8.91$ \\
\hline 1 & 5 & $20.50-29.50$ & $24.14 \pm 3.79$ & 14 & $31.10-69.80$ & $45.44 \pm 11.18$ & 16 & $33.00-59.30$ & $42.91 \pm 8.52$ \\
\hline 2 & - & - & - & 6 & $38.70-65.70$ & $51.65 \pm 10.94$ & 9 & $31.70-65.20$ & $46.22 \pm 11.48$ \\
\hline 3 & - & - & - & 1 & 65.10 & - & 3 & $38.10-51.90$ & $44.03 \pm 7.10$ \\
\hline 4 & - & - & - & 1 & 89.1 & - & 1 & 61.50 & - \\
\hline 5 & - & - & - & 1 & 75.5 & - & - & - & - \\
\hline Total & 23 & & & 37 & & & 42 & & \\
\hline
\end{tabular}




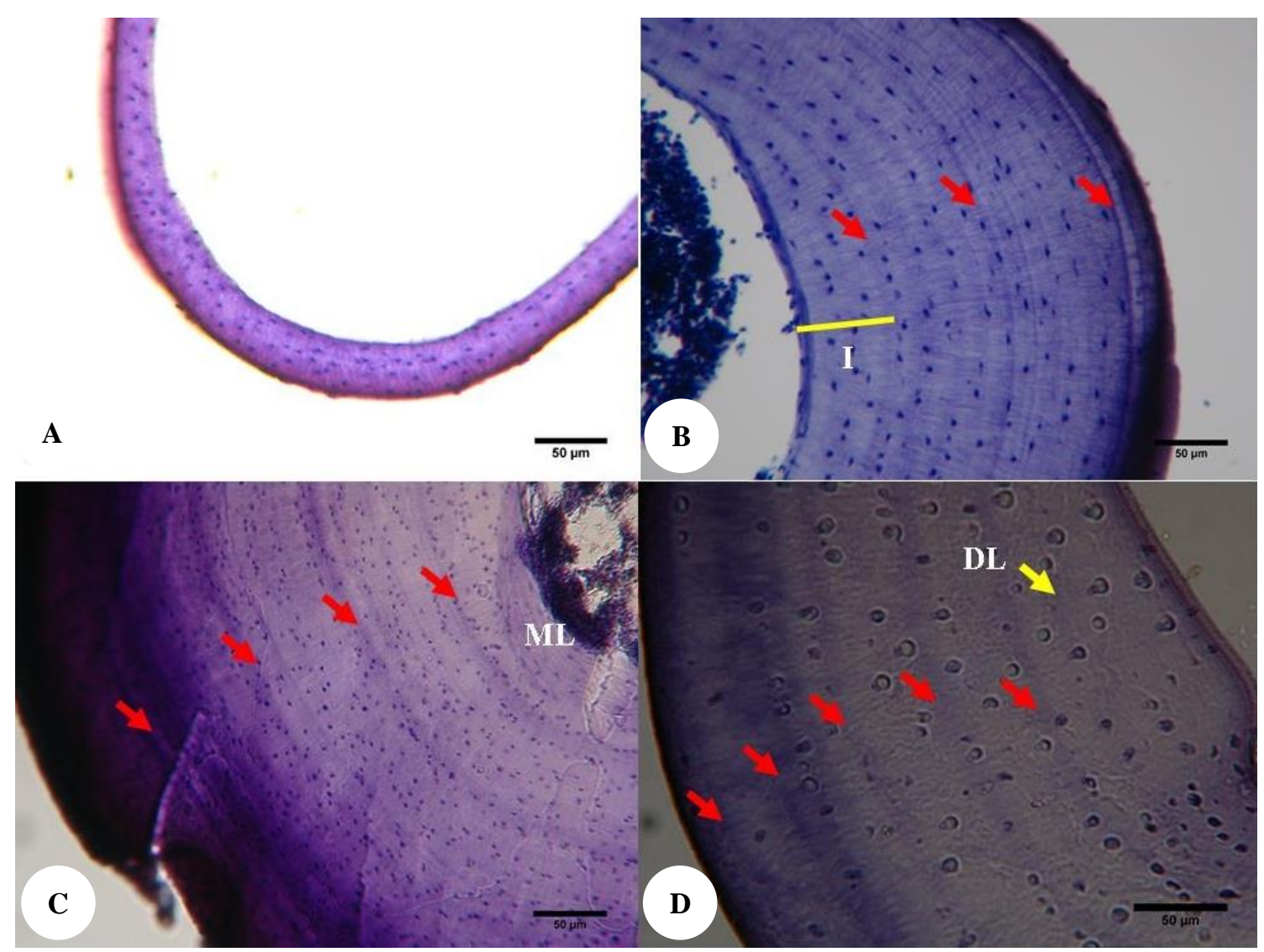

Figure 1. Femur bone cross section of: A. Pre-adult, $20.3 \mathrm{~mm}$ in SVL, showing 0 LAG; B. Adult female, $42.1 \mathrm{~mm}$ in SVL, showing 3 LAGs; C. Adult male, $61.5 \mathrm{~mm}$ in SVL, showing 4 LAGs with endosteal resorption at ML; D. Adult female, $75.5 \mathrm{~mm}$ in SVL, showing 5 LAGs. ML: Metamorphosis Line; DL: Discontinue Line (yellow arrow); I: Interval, width between continue line. Red arrow: LAG
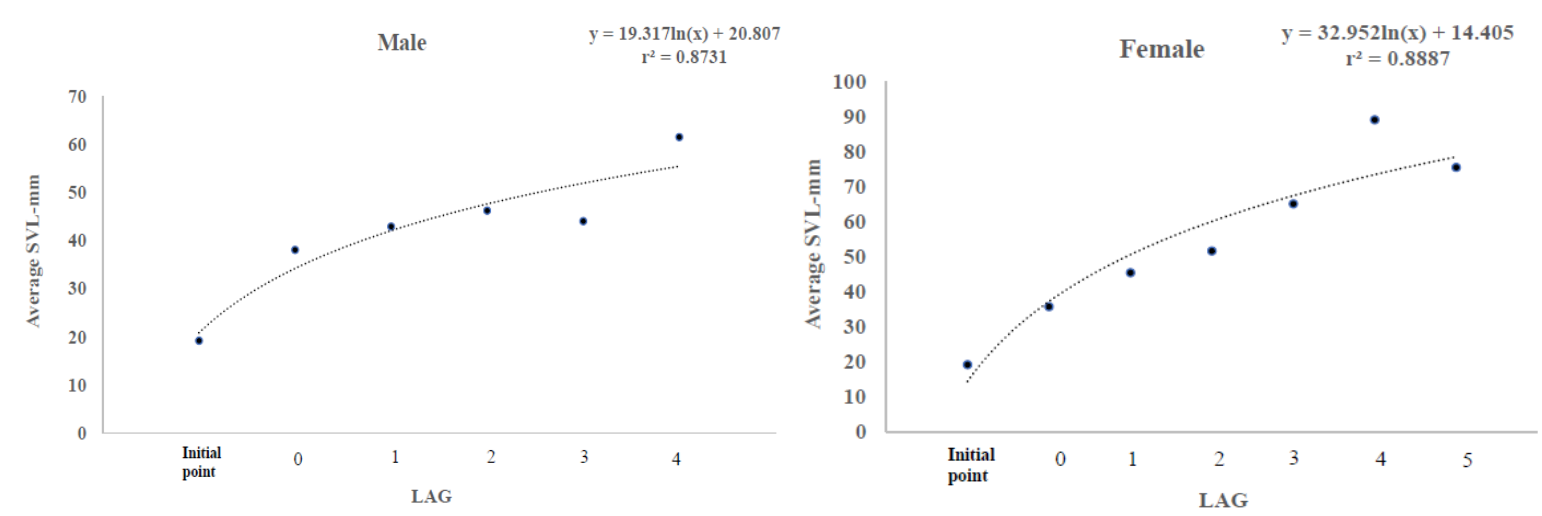

Figure 2. Von Bertalanffy curves between average SVL and the number of LAGs on the adult male group (left) and adult female group (right)

Endosteal resorptions were found in 15 individuals (5 adult males with range of age 2-4; 10 adults females with range of age 1-5). The interval width between MI and the first LAG varies greatly between the three groups. The cross-section showed that at the interval there is a discontinuous line (DL), the line similar to LAG, but not completely circular; the line presented in most individuals (Figure 1); of the 102 individuals there were 0 DLs as many as 8 individuals; 1 DL as many as 18 individuals; 2 DL as many as 20 individuals and 3 DL as many as 8 individuals; 4 DL as many as 2 individuals; however, individuals which have not yet formed LAG have DL between 0-3; while the formation of DL in the next LAG is not as many at the first interval.

SVL length for adult male and adult female groups under one year with 0 LAGs were not significantly 
different (Welch $\mathrm{F}$ test in the case of unequal variances: $\mathrm{F}=0.7356, \mathrm{df}=16.44, \mathrm{p}=0.4034)$. However, after one year, the length of SVL of adult males is not also significantly different than adult females (Welch $F$ test in the case of unequal variances: $\mathrm{F}=0.4755, \mathrm{df}=24.16, \mathrm{p}=0.497 ; \mathrm{n}$ of male $=16 ; \mathrm{n}$ of female $=14$ ), as well as for adult males and adult females that are more than two years old (Welch $\mathrm{F}$ test in the case of unequal variances: $\mathrm{F}=0.8517, \mathrm{df}=11.25$, $\mathrm{p}=0.3754 ; \mathrm{n}$ for male $=9 ; \mathrm{n}$ for female=6). This result showed that adult females have a similar body size as adult males, this result was totally different from its close relative $F$. limnocharis (Shou et al. 2005).

\section{Discussion}

Skeletochronology technique was successfully applied for femur bone of $F$. cancrivora, which improved the results that had been done by Kusrini and Alford (2006) for the same species. The success of the skeletochronology technique also proved in F. limnocharis (Liao et al. 2011; Pancharatna and Deshpande 2003; Phadmacanty et al. 2018 ) which is a close relative to $F$. cancrivora. The number of LAG compared with the length of SVL at the pre-adult stage, adult males and adult females showed accurate results with a strong correlation between the two parameters. However, this study found several adult individuals who have entered the adult stage but do not have LAGs or pre-adult individuals but have one LAG (see Table 1; Andreone et al. 2011; Li et al. 2010; Kumbar and Pancharatna 2001; Kumbar and Pancharatna 2002; Kumbar and Lad 2017). Generally, the increase in SVL length was positively correlated with the increase in the number of LAGs. Following Andreone et al. (2011), Li et al. (2010), Kumbar and Pancharatna (2001), Kumbar and Pancharatna (2002) and Kumbar and Lad (2017), the absence of LAG was because the individual was not yet one year old, or it could also be due to the process of the bone formation so that there was no accumulation of calcium in the bones that produced LAG (Stiffler 1993). These result indicate that the formation of LAG were not only influence by internal factor but also by external factor included environmental and nutrition.

The maturity of individuals entering the adult stage can run ahead of the formation of the first LAG. Usually, the LAG formation is caused by genetic factors and circannual rhythm under natural condition reinforced by the seasonal cycle. In the case of Microhyla ornata, LAGs are reported to be formed by the annual rainfall pattern which may affect regular feeding activity (Kumbar and Pancharatna 2001). On the other hand, LAGs of Rana latastei living in the temperate area are produced when the individual overwinters (Guarino et al. 2003), LAGs Ceratophrys cranwelli and Dermatonotus muelleri in laboratory conditions are estimated to be formed by general intrinsic (genetic) control (Marangoni et al. 2009). Paddy fields in areas where these frogs were collected applied to a harvesting system three times a year. So, the availability of water in rice fields was very dynamic which caused stress to frogs that live there; this may cause the reabsorbtion of earlier formed LAG (Stiffler 1993); these were proven of endosteal absorption in young age in several individuals.
The intensity of LAGs was less visible on F. cancrivora in this study, compared with frogs from the temperate region Hylarana guantheri (Li et al. 2010). This finding supports Castanet and Smirina (1990) assumption that LAGs can be more or less visible in life specimens' bones that live under constant climatic conditions.

Our results showed that body size is not a good indicator for age estimation on F. cancrivora; this tendency is also reported by another author (Khonsue et al. 2000). Bell and Zamudio (2002) reported that in anurans, the most common sexual dimorphism is in body size. In most anuran species, it showed females larger than males (Woolbright 1983). Similar to that report, female $F$. cancrivora are significantly larger than males (Iskandar 1998). Larger body size occurs in female frogs because of natural selection to improve fecundity or offspring size (Liu et al. 2012). It seems to be the specimens that were used as the research material in this study (high number of individuals with LAGs between 0-2) have not been sufficient to explain the growth rates of male and female bodies, so that the SVL length of males and females does not look significantly different.

The longevity of $F$. cancrivora that were collected in the paddy field of Karawang District was estimated to be at least five years in the female and four years in the male. The Karawang District is one of the hunting sites of $F$. cancrivora for consumption purposes, so it was very difficult to get a frog size above $100 \mathrm{~mm}$, which possibly can explain the maximum lifespan of this frog.

\section{ACKNOWLEDGEMENTS}

We are grateful to Dr. Amir Hamidy as coordinator of the project. Many thanks are also addressed to Wahyu Tri Laksono and Syaripudin for their help in the field. We thank Karen Mulyono for English editing. This research was supported by LIPI's Project in 2018 under KSKCITES with the code of the sub-project was 3400.002.051.A. All authors (NLPRP and HK) contributed equally to this work.

\section{REFERENCES}

Andreone FC, Giacoma FM, Mercurio V. Tessa G. 2011. Age profile in nine Mantella poison frogs from Madagascar, as revealed by skeletochronological analyses. Alytes 27 (3): 73-84.

Bell RC, Zamudio KR. 2012. Sexual dichromatism in frogs: natural selection, sexual selection and unexpected diversity. Proc R Soc B Biol Sci 279: 4687-4693.

Castanet J, Francillon-Vieillot H, Bruce RC. 1996. Age estimation in Desmognathine salamenders assessed by skeletochronology. Herpetologica 52 (2): 160-171.

Eden CJ, Whiteman HH, Duobinis-Gray L, Wissinger SA. 2007. Accuracy assessment of skeletochronology in the Arizona tiger salamander (Ambystoma tigrinum nebulosum). Copeia 2007 (2): 471477.

Guarino FM, Erismis UC. 2008. Age determination and growth by skeletochronology of Rana holtzi, an endemic frog from Turkey. Italian J Zool 75 (3): 237-242.

Guarino FM, Lunardi S, Carlomagno M, Mazzotti S. 2003. A skeletochronological study of growth, longevity, and age at sexual 
maturity in a population of Rana latastei (Amphibia, Anura). J Biosci 28 (6): 775-782.

Hammer Ø, Harper DAT, Ryan PD. 2001. PAST: Paleontological statistics software package for education and data analysis. Palaeontologia Electronica 4 (1): 9.

Hasumi M. 2010. Age, body size, and sexual dimorphism in size and shape in Salamandrella keyserlingii (Caudata: Hynobiidae). Evol Biol 37: 38-48.

Iskandar DT. 1998. Amphibians of Java and Bali. Research Center for Biology, LIPI, Bogor.

Khonsue W, Matsui M, Misawa Y. 2000. Age determination by skeletochronology of Rana nigrovittata, a frog from tropical forest of Thailand. Zoological Science 17: 253-257.

Kumbar SM, Lad SB. 2017. Determination of age and longevity of road mortal Indian common toad Duttaphrynus melanostictus by skeletochronology. Russian J Herpetol 24 (3): 217-222.

Kumbar SM, Pancharatna K. 2001. Determination of age, longevity, and age at a reproduction of the frog Microhyla ornata by skeletochronology. J Biosci 26 (2): 265-270.

Kumbar SM, Pancharatna K. 2002. Annual growth layers in the phalanges of the Indian skipper frog Rana cyanophlyctis (Schn.). Copeia 2002 (3): $870-872$

Kurniati H. 2003. Amphibians and reptiles of Gunung Halimun Nationa Park, West Java, Indonesia. Research Center for Biology-LIPI Cibinong.

Kusrini MD, Alford RA. 2006. The application of skeletochronology to estimate ages of three species of frogs in West Java, Indonesia. Herpetol Rev 37 (4): 423-425.

Kusrini MD. 2013). Panduan bergambar identifikasi amfibi Jawa Barat. Fakultas Kehutanan, Institut Pertnian Bogor \& Direktorat Konservasi dan Keanekaragaman Hayati, Bogor. [Indonesia].

Kutrup B, Bulbul U, Yilmaz N. 2005. Age structure in two populations of Triturus vittatus ophryticus at different altitudes. Amphibia-Reptilia 26: 49-54.

Li C, Liao WB, Yang ZS. Zhou CQ. 2010. A skeletochronological estimation of age structure in a population of the Guenther's frog, Hylarana guentheri, from western China. Acta Herpetolica 5 (1): 111

Liao WB, Lu X, Shen YW, Hu JC. 2011. Age structure and body size of two populations of the rice frog Rana limnocharis from different altitudes. Italian J Zool 78 (2): 215-221.
Liao WB, Lu X. 2010a. Age and growth of a subtropical high-elevation torrent frog, Amolops mantzorum, western China. J Herpetol 44 (1): 172-176.

Liao WB, Lu X. 2010b. Age structure and body size of the Chuanxi Tree Frog Hyla annectans chuanxiensis from two different elevations in Sichuan (China). Zoologischer Anzeiger 248: 255-263.

Liu YH, Zeng Y, Liao WB, Zhou CQ, Mi ZP, Mao M, Chen L. 2012. Altitudinal variation in body size in the rice frog (Rana limnocharis) in southwestern China. Acta Herpetologica 7 (10): 57-68.

Marangoni F, Scgaefer E, Cajade R, Tejedo M. 2009. Growth-Mark Formation and Chronology of Two Neotropical Anuran Species. J Herpetology 43 (3): 546-550.

Morrison C, Hero JM, Browning J. 2004. Altitudinal variation in the age at maturity, longevity, and reproductive lifespan of anurans in subtropical Queensland. Herpetologica 60 (1): 34-44.

Olgun K, Uzum N, Avci A, Miaud C. 2005. Age, size and growth of the southern crested newt Triturus karelinii (Strauch 1870) in a population from Bozdag (Western Turkey). Amphibia-Reptilia 26: 223-230.

Oromi N, Sanuy D, Sinsch U. 2012. Altitudinal variation of demographic L-history traits does not mimic latitudinal variation in natterjack toads (Bufo calamita). Zoology 115: 30-37.

Pancharatna K, Deshpande SA. 2003. Skeletochronological data on age, body size and mass in the Indian Cricket Frog Limnonectes limnocharis (Boie, 1835) (Anura: Ranidae). Herpetozoa 16 (1/2): 41 50 .

Phadmacanty NLPR, Hamidy A, Semiadi G. 2018. Skeletochronology of Asian grass frog Fejervarya limnocharis (Gravenhorst, 1829) from Java to support management conservation. Treubia 45: 1-10.

Rocha CFD. 1995. Growth of the tropical sand lizard Liolaemus lutzae in southern Brazil. Amphibia-Reptilia 16: 257-264.

Shou L, Du WG, Shu L. 2005. Sexual dimorphism and fecundity in the gold-stripe pond frog (Pelophylax plancyi) and the terrestrial frog (Fejervarya limnocharis). Acta Ecologica Sinica 25 (4): 664-668.

Sinsch U, Dehling JM. 2017. Tropical anurans mature early and die young: Evidence from eight Afromontane Hyperolius species and a meta-analysis. PLoS ONE 12 (2): e0171666. DOI: 10.1371/journal.pone.0171666.

Sinsch U. 2015. Review: Skeletochronological assessment of demographic life-history traits in amphibians. Herpetol J 25 (1): 5-13.

Stiffler DF. 1993. Amphibian calcium metabolism. J Exp Biol 184: 47-61.

Woolbright LL. 1983. Sexual selection and size dimorphism in Anura amphibia. Am Nat 121 (1): 110-119. 